\title{
EVALUASI PEMBELAJARAN MATA KULIAH AL-ISLAM DAN \\ KEMUHAMMADIYAHAN SEBAGAI INTERNALISASI PENGUATAN PENDIDIKAN KARAKTER MAHASISWA PRODI PAI DI UNIVERSITAS MUHAMMADIYAH TANGERANG
}

\author{
Milana Abdillah Subarkah* Agus Salim** \\ milana.abdillah@umt.ac.id, bani.samudra@gmail.com \\ *Dosen PAI, Universitas Muhammadiyah Tangerang \\ **Dosen PAI, Universitas Muhammadiyah Tangerang
}

\begin{abstract}
The phenomenon of education in higher education for students is able to contribute to the aspects of temperament. This is due to various kinds of influences in social life that are currently undergoing many changes. The change in question is an evaluation of learning by integrating character education. Character education can be realized in the regulatory system applied to educational institutions including tertiary institutions. Policy makers have a major contribution as education practitioners, and are also the spearhead of the success of achieving character education for students. This study tries to describe the implementation of learning evaluation of Al-Islam and Kemuhammadiyahan (AIK) courses at the PAI Study Program at the Muhammadiyah University of Tangerang as a reinforcement of character education at Muhammadiyah colleges. The procedure of this research is by observing the activities of lecturers and students when learning takes place then analyzing whether the implementation of evaluation in the faith-based learning is able to foster student character education.
\end{abstract}

Keywords: Evaluation, Character Education

\section{A. PENDAHULUAN}

Pendidikan Islam adalah salah satu aspek terpenting untuk diterapkan dalam penanaman nilai karakter peserta didik baik di sekolah maupun di perguruan tinggi. Hal tersebut merupakan suatu kebutuhan dalam hidup umat Islam ditengah-tengah maraknya penyimpangan prilaku dalam kehidupan bermasyarakat (Chabib Thoha, dkk, 1999).

Beberapa nilai pendidikan Islam diantaranya kejujuran, tanggung jawab, disiplin, dan sikap religiusitas yang telah menjadi karakter bangsa Indonesia selama ini seolah-olah menjadi suatu yang asing untuk dijumpai ditengah-tengah masyarakat. Situasi seperti ini akan diperparah lagi jika tidak segera berupaya mengembangkan program-program pendidikan Islam pada lembaga pendidikan yang bersifat jangka panjang maupun jangka pendek (Nur Ainiyah, 2013: 26).

Sebagaimana dari hasil pengamatan, masih terdapat sikap atau prilaku mahasiswa yang ada dari beberapa kampus di Kota Tangerang, belum mampu menunjukkan nilai-nilai karekter yang sudah semestinya dapat di realisasikan dalam kehidupan sehari-hari. Tindakan seperti menyontek saat ujian, perasaan tidak percaya diri, sikap individualistis, hedonistik, dan lain sebagainya pemandangan seperti ini masih kerap terjadi, padahal matakuliah tentang

Tadarus Tarbawy. Vol. 2 No. 1 Jan - Jun 2020. ISSN. 2657-1285 e-ISSN. 2656-8756 
pendidikan Islam telah disampaikan sekurang-kuranganya dua semester.

Dari berbagai permasalahan di atas, perguruan tinggi Muhammadiyah memiliki konsep pendidikan yang dikenal dengan istilah caturdharma perguruan tinggi yang meliputi pendidikan, penelitian, pengabdian masyarakat, dan Al-Islam dan Kemuhammadiyahan. Yang membedakan perguruan tinggi lain baik negeri maupun swasta dengan perguruan tinggi Muhammadiyah adalah konsep pendidikan yang berbasis Al-Islam dan Kemuhammadiyahan.

Hal ini dikarenakan Muhammadiyah sebagai organisasi kemasyarakatan yang concern pada dunia pendidikan memiliki kepentingan dan memandang bahwa dakwah yang paling strategis untuk disampaikan adalah memalui pendidikan, jika dibandingkan dengan lembaga lainnya seperti amal usaha dibidang kesehatan dan ekonomi, jumlah lembaga pendidikan jauh lebih banyak sehingga Muhmmadiyah hampir identik dengan pendidikan, (Syamsul Arifin, 2005:202).

Dengan menerapkan pendidikan berbasis Al-Islam dan Kemuhammadiyahan bagi mahasiswa di perguruan tinggi Muhammadiyah, maka diharapkan mampu mengakomodir peningkatan pendidikan karakter mahasiswa. Sehingga mahasiswa dapat mengidupkan nilai-nilai pendidikan Islam menjadi insan yang beragama dan bertakwa dalam menghadapi tantangan jaman yang terus berubah. Mata kuliah AlIslam dan Kemuhammadiyahan memberikan pemahaman kepada mahasiswa tentang paham agama menurut Muhammadiyah, tauhid, dan pendidikan karakter yang berlandaskan Al-Qur'an dan Hadist. Nilai pendidikan Al-Islam dan Kemuhammadiyahan yang disampaikan kepada setiap mahasiswa semester III dan IV pada Prodi PAI di Universitas Muhammadiyah Tangerang berorientasi pada seluruh aktivitas pendidikan, penelitian, dan pengabdian masyarakat dengan maksud untuk memberikan tuntunan kepada mahasiswa agar menjadikan ajaran agama Islam sebagai prinsip hidupnya, (Amelia dan Kuncahyono, 2018).

Sebagaimana penjelasan di atas, maka penulis tertarik untuk meneliti tentang bagaimana pelaksanaan mata kuliah AlIslam dan Kemuhammadiyahan dalam menguatkan pendidikan karakter mahasiswa serta bagaimana evaluasi yang dilakukan para dosen pada setiap pembelajaran AlIslam dan Kemuhammadiyahan. Dengan demikian penulis melakukan penelitian di Universitas Muhammadiyah Tangerang dengan judul "Evaluasi Pembelajaran Mata Kuliah Al-Islam Dan Kemuhammadiyahan Sebagai Internalisasi Penguatan Pendidikan Karakter Mahasiswa Prodi PAI Di Universitas Muhammadiyah Tangerang”.

\section{B. METODE PENELITIAN}

Dalam melakukan penelitian ini menggunakan penelitian deskriptif (Sukmadinata, 2005). Yaitu mengamati berbagai kejadian yang terjadi. Penelitian ini akan mendeskripsikan pelaksanaan evaluasi pembelajaran mata kuliah Al-Islam dan Kemuhammadiyahan dalam upaya peningkatan pendidikan karakter di Universitas Muhammadiyah Tangerang. Adapun prosedur yang dilakukan adalah dengan mencermati aktivitas dosen dan mahasiswa saat berlangsung pembelajaran AIK serta menganalisis kegiatan apakah evaluasi pembelajaran mata kuliah AIK mampu menumbuhkan pendidikan karakter mahasiswa.

Kemudian, melakukan desain deskriptif survei, digunakan untuk menguji hipotesis dan penggunaan statistik deskriptif (proporsi, mean/ rata-rata, median, modus, frekuensi, kuartil, dan sebagainya) untuk mengamati apa yang terjadi, biasanya tidak 
untuk menerima atau menolak hipotesis (Sukmadinata, 2005). Pengumpulan data dengan teknik observasi, dokumentasi, dan wawancara. Teknik obsevasi dilakukan untuk mengetahui aktivitas evaluasi pembelajaran mata kuliah AIK oleh dosen. Selain itu, pembagian angket untuk mengatahui pelaksanaan evaluasi mata kuliah AIK yang ditunjukkan dengan indikator-indikator yang relevan. Wawancara, dilakukan kepada para dosen AIK untuk mengetahui evaluasi pembelajaran AIK, kendala yang dihadapi dan pemecahan terkait kendala dalam implementasi evaluasi pembelajaran di kelas. Dokumentasi, dilakukan untuk mendapatkan data atau peristiwa yang terjadi pada saat proses pembelajaran berlangsung.

\section{HASIL DAN PEMBAHASAN}

\section{Pendidikan}

Kemuhammadiyahan

kuliah wajib di Al-Islam dan
merupakan mata Muhammadiyah persyarikatan Muhammadiyah. Menurut Ahmad Dahlan, pendidikan akhlak adalah modal dasar dalam membangun bangsa selain pendidikan individu dan pendidikan sosial. Dalam pendidikan Kemuhammadiyahan inilah mahasiswa pada Prodi PAI di Universitas Muhammadiyah Tangerang diperkenalkan dengan nilai-nilai Islam dan nilai-nilai organisasi Muhammadiyah sehingga mereka kelak dengan suka rela mengamalkan dan menghayati prinsip-prinsip keyakinan dan cita-cita Muhammadiyah. Hal ini sebagaimana pengamatan pada pembelajaran AIK yang disampaikan kepada para mahasiswa antara lain dengan metode internalisasi dalam kegiatan pembelajaran; keteladanan, praktek penugasan mata kuliah, dan pembiasaan/ kedisiplinan, (Silvie dan Kurnia, 2018).
Pendidikan Al-Islam dan Kumuhammadiyahan penyiapan lingkungan yang memungkinkan seseorang tumbuh sebagai manusia yang menyadari kehadiran Allah Swt sebagai Robb dan menguasai ilmu pengetahuan, teknologi dan seni (IPTEKS). Dengan kesadaran spiritual makrifat (iman/ tauhid) dan pengusaan IPTEKS, seseorang mampu memenuhi kebutuhan hidupnya secara mandiri, peduli sesama yang menderita akibat kebodohan dan kemiskinan, senantiasa menyebarluaskan kemakrufan, mencegah kemungkaran bagi pemuliaan kemanusiaan dalam kerangka kehidupan bersama yang ramah lingkungan dalam sebuah bangsa dan tata pergaulan dunia yang adil, beradab dan sejahtera sebagai ibadah kepada Allah, (Sri Winarni, 2013).

\section{Pendidikan Muhammadiyah} merupakan pendidikan Islam modern yang mengintegrasikan agama dengan kehidupan dan antara iman dan kemajuan yang holistik. Dari rahim pendidikan Muhammadiyah diharapkan lahir generasi muslim terpelajar yang kuat iman dan kepribadiannya, sekaligus mampu menghadapi dan menjawab tantangan zaman. Inilah pendidikan Islam yang berkemajuan. IPTEKS adalah hasil pemikiran rasional secara holistik dan komprehensif atas realitas alam semesta (ayat kauniyah) dan atas wahyu dan sunnah (ayat qauliyah) yang merupakan satu kesatuan (Puspita Handayani).

Maka Al-Islam dan

Kemuhammadiyahan (AIK) merupakan mata kuliah wajib bagi semua Universitas Muhammadiyah se-Indonesia, termasuk Prodi PAI Universitas Muhammadiyah Tangerang yang ditempuh selama dua semester, dengan rincian semester III/ AIK1 (Ideologi Muhammadiyah) dan semester IV/ AIK2 (Pemberdayaan Dhuafa). Dikarenakan Prodi PAI merupakan program studi yang mayoritas pembahasan/mata kuliahnya tentang nilai-nilai ajaran Islam, maka untuk 
mengisi pembelajaran Kemuhammadiyahan, hanya ada pada semester III dan IV saja.

Kemudian, dari segi kompetensi lulusan pendidikan Al-Islam dan Kemuhammadiyahan (AIK) beberapa pencapaian yang diharapkan dari pendidikan AIK adalah sebagai berikut:

a. Mampu menerapkan prinsip hidup Islami yang didasrkan pada pemahaman dan pengamalan ajaran tauhid yang murni dan akhlak utama berupa amanah dan tanggung jawab, kebersamaan, kejujuran, kedisiplinan, keadilan, mawas diri, tulus ikhlas, kepedulian, dan profesionalitas yang didasarkan pada pemahaman nilainilai ajaran Islam yang sesuai dengan faham Muhammadiyah sehingga dapat menjadi pribadi merdeka, berkemajuan dan menjauhkan dari segala hal yang bersifat syirik, takhayul dan khurafat serta siap menjadi teladan (uswatun hasanah).

b. Mampu melaksanakan ibadah mahdah dan amal shalih yang didasari oleh pemahaman dan penghayatan yang tepat terhadap al-Qur'an dan as-Sunnah Maqbulah sehingga dapat berkarya nyata dan bermanfaat bagi kehidupan umat manusia (rahmatan lil'alamin).

c. Mampu menerapkan prinsip hidup sesuai paham Muhammadiyah yang berdasarkan al-Qurán dan as-Sunnah al-Maqbullah sehingga menjadi pribadi yang memiliki sikap hidup berkemajuan dan mau berjuang dalam kehidupan masyarakat (Khilmiyah dan Syamsudin, 2016: 6).

Mata kuliah AIK1 pada semester III, sebagaimana tema-tema pembahasan yang terdapat di silabus dan RPS, yakni membahas tentang historis Ajaran Islam pada masa Rasulullah Saw sampai ke pembahasan berdirinya persyarikatan Muhammadiyah. Pembahasan tersebut bertujuan untuk memberikan wawasan keIslaman melalui pendekatan pembelajaran yang aktif dan menyenangkan. Sehingga mahasiswa mampu menyerap materi perkuliahan yang disampaikan oleh dosen pengampu mata kuliah AIK1.

Adapun AIK2 yang merupakan pembahasan di semester IV, menjelaskan tentang dakwah Al-Maun. Sebagaimana dalam firman Allah Swt.

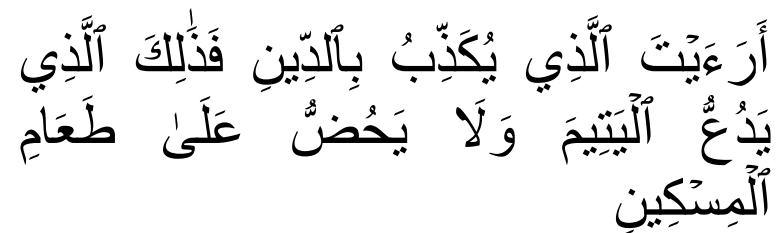

"Tahukah kamu (orang) yang mendustakan agama?, Itulah orang yang menghardik anak yatim, dan tidak menganjurkan memberi makan orang miskin." (Qs. AlMaun: 1-3)

Ayat tersebut menjelaskan perihal umat Islam yang tidak mau mempedulikan anak yatim dan orang miskin dinilai sebagai pendusta agama. Maka penanaman nilai pendidikan dalam surat Al-Maun adalah agar mahasiswa dapat mengamati lebih mendalam tentang perjuangan KH. Ahmad Dahlan pada saat awal mula dakwah Muhammadiyah di syiarkan kepada masyarakat Yogtakarta memberikan kepeduliannya kepada kaum mustad'afin. Tidak hanya sampai disitu, mahasiswa juga diminta untuk melakukan praktek lapangan yakni memberikan kepedulian kepada masyarakat dhuafa yang berada disekitar lingkungannya.

Melalui mata kuliah AIK sebagaimana penjelasan di atas, dapat dipahami bahwa pembelajaran AIK tidak hanya fokus kepada aspek kognitif dan psikomotorik saja, akan tetapi menyentuh pada ranah afektif. Maka mata kuliah AIK yang telah menjadi bagian dari kurikulum Prodi PAI juga didalamnya tedapat nilai pendidikan karakter. Hal ini merupakan upaya yang dirancang dan dilaksanakan secara sistematis untuk membantu mahasiswa memahami nilai-nilai perilaku manusia yang berhubungan dengan Tuhan YME, diri sendiri, sesama manusia, 
lingkungan, dan kebangsaan yang terwujud dalam pikiran, sikap, perkataan dan perbuatan, yang berdasarkan norma agama, hukum, tatakrama, budaya, dan adat istiadat (Puspita Handayani).

Pendidikan karakter adalah dua kata yang memiliki arti yang berbeda. Pendidikan adalah proses internalisasi budaya ke dalam diri seseorang dan masyarakat sehingga membuat orang dan masyarakat jadi beradab. Pendidikan bukan merupakan sarana transfer ilmu pengetahuan saja, tetapi lebih luas lagi yakni sebagai sarana pembudayaan dan penyaluran nilai (enkulturisasi dan sosialisasi).

Perpaduan dua kata antara pendidikan dan karakter memiliki makna yang sangat mendalam jika dipadukan. Adapun pengertian pendidikan karakter menurut para ahli diantaranya sebagai berikut: Pendidikan Karakter menurut Megawangi dalam Milana adalah sebuah usaha untuk mendidik anakanak agar dapat mengambil keputusan dengan bijak dan mengaplikasikan hal tersebut dalam kehidupan sehari-harinya, sehingga mereka dapat memberikan sumbangsih yang positif kepada lingkungan sekitarnya. Nilai-nilai karakter yang perlu ditanamkan kepada anak-anak adalah nilainilai universal yang mana seluruh agama, tradisi, dan budaya pasti menjunjung tinggi nilai-nilai tersebut. Nilai-nilai universal ini harus dapat menjadi perekat bagi seluruh anggota masyarakat walaupun berbeda latar belakang budaya, suku, dan agama (Milana Abdillah Subarkah, 2019:85).

Dalam keseharian, karakter seseorang akan membawa dampak pada sekeliling. Seseorang dengan karakter kuat bisa mendominasi dan menjadi pemimpin sekitarnya. Orang yang sukses mimiliki karakter yang positif. Dia akan berusaha menjaga keseimbangan dan perkembangan dirinya dengan meningkatkan kualitas, keimanan, akhlak, hubungan dengan sesama dan kegiatan yang memiliki nilai manfaat untuk mewujudkan impiannya.

Pembentukan karakter seseorang bukan hal yang mudah, diperlukan sebuah pembiasaan yang dilakukan secara nyata, melalui tindakan yang konsisten dan berkesinambungan. Metode pembentukan karakter yang diungkap oleh asteven $\mathrm{R}$. Covey dalam bukunya Tujuh Kebiasaan Manusia yang Efektif "Taburlah gagasan, petiklah perbuatan,. Taburlah perbuatan, petiklah kebiasaan.Taburlah kebiasaan, petiklah karakter.Taburlah karakter petiklah hasil".

Istilah karakter dihubungkan dan dipertukarkan dengan istilah etika, akhlak, dan atau nilai dan berkaitan dengan kekuatan moral, berkonotasi "positif" bukan netral. Oleh karena itu Pendidikan karakter secara lebih luas dapat diartikan sebagai pendidikan yang mengembangkan nilai budaya dan karakter bangsa pada diri peserta didik sehingga mereka memiliki nilai dan karakter sebagai karakter dirinya, menerapkan nilai-nilai tersebut dalam kehidupan dirinya sebagai anggota masyarakat, dan warga negara yang religius, nasionalis, produktif, dan kreatif.

Konsep tersebut harus disikapi secara serius oleh pemerintah dan masyarakat sebagai jawaban dari kondisi riil yang dihadapi bangsa Indonesia akhir-akhir ini yang ditandai dengan maraknya tindakan kriminalitas, memudarnya nasionalisme, munculnya rasisme, memudarnya toleransi beragama serta hilangnya religiusitas dimasyarakat, agar nilai- nilai budaya bangsa yang telah memudar tersebut dapat kembali membudaya ditengah-tengah masyarakat. Salah satu upaya yang dapat segera dilakukan adalah memperbaiki kurikulum dalam sistem pendidikan nasional yang mengarahkan pada pendidikan karakter secara nyata.

Dalam Islam sebenarnya pendidikan karakter sudah diajarkan pada masa 
Rasulullah Saw ketika beliau mengajarkan kepada para sahabat dengan model Uswah (contoh), yaitu para sahabat mengamati apa yang dilakukan Rasulullah Saw, kemudian melaksanakanya, selanjutnya menjadi suatu kebiasaan. Seperti pertama kali perintah shalat, sabda Rasulullah:"Shalatlah kamu seperti shalatku" (HR. Muslim) amalan shalat dicontohkan Rasul ditiru para sahabat dan menjadi rutinitas amal ibadah umat Islam. Hal inilah salah satu bentuk pendidikan karakter yang diajarkan Rasulullah Saw.

Secara umum ada tiga model pembelajaran : pembelajaran yang terpusat pada bahan ajar (subject matter center learning), pendidikan yang terpusat pada dosen(teacher center learning), dan pendidikan terpusat pada mahasiswa (student center learning). Pembelajaran AIK yang mengedepankan ilmu-ilmu agama dan berorientasi pada padat isi cenderung menerapkan model pendidikan yang berpusat pada materi: AIK bersifat normatif dan doktriner cenderung menerapkan model pembelajaran yang berpusat pada dosen, dan AIK yang integrated dengan kehidupan dan interkoneksitas dengan mata kuliah lain akan cendereung menggunakan model pendidikan yang berpusat pada mahasiswa.

Penanaman pendidikan karakter pada mata kuliah AIK, diharapkan mampu memberikan keterampilan untuk menciptakan Karakter pribadi yang unggul. Bagaimanakah membangun kebiasaan yang dapat menciptakan pribadi berkarakter, maka dimulai dengan langkah sederhana, dalam kurikulum AIK1 (Ideologi Muhammadiyah) ada perjalanan dakwah Islam pada masa Rasulullah Saw dan dilanjutkan oleh Khulafaur Rasyidin. Diantaranya: Pertama, Menyampaikan pengetahuan tentang kesabaran dan kegigihan Rasulullah Saw. Kedua, Menanamkan keyakinan sikap optimis, dan Ketiga, Menanamkan pada mahasiswa untuk berfikir positif dalam keadaan dan kondisi apapun jangan mudah putus asa, sebagaimana perjuangan Nabi Muhammad Saw dan perjuangan KH. Ahmad Dahlan dalam mensyiarkan dakwah Islam pasti ada tantangan dan hambatannya. Sementara itu, pada mata kuliah AIK2, mahasiswa di arahkan untuk dapat merealisasikan pesan yang terkandung dalam Al-Qur'an surat AlMaun, diantaranya adalah Pertama, larangan menghardik anak yatim dan memberikan kepedulian kepada mereka yang yatim, Kedua, memberi makan dan berbagi kepada fakir miskin. Sehingga dengan pendidikan karakter tersebut mahasiswa benar-benar memahami pembelajaran Al-Islam dan Kemuhammadiyahan. Setelah proses pembelajaran AIK pada Prodi PAI di Universitas Muhammadiyah Tangerang berlangsung. Maka hal yang paling penting dari kegiatan belajar dan mengajar adalah mengevaluasi pembelajaran AIK.

Pengertian evaluasi pembelajaran adalah pengumpulan kenyataan secara sistematis dalam menetapkan apakah terjadi perubahan pada kenyataan dalam diri seorang peserta didik. Bisa juga merupakan proses menggambarkan, memperoleh hingga menyajikan informasi menilai alternatif keputusan. Evaluasi memiliki tujuan yang berbeda dalam setiap ujian, sederhanannya evaluasi digunakan untuk memperbaiki sistem. Caranya adalah dengan memberi penilaian berdasarkan data yang diambil dari sekelompok atau suatu objek.

Evaluasi pendidikan AIK perlu dikembangkan pada evaluasi yang bersifat portofolio, yaitu evaluasi yang mencakup proses, hasil dan umpan balik. Evaluasi bukan saja menjadi hak preogatif dosen, mahasiswa pun juga berhak menilai apa dan bagaimana proses dan hasil pembelajaran yang selama ini dilaksanakan. Mereka dapat menilai kesungguhan, keterlibatan, kreativitas dan hasil belajarnya. Sedangkan evaluasi hasil belajar diarahkan untuk 
mendapatkan data yang akan dijadikan sebagai bukti mengenai taraf perkembangan atau kemajuan belajar yang capai oleh mahasiswa Prodi PAI, setelah mereka mengikuti proses pembelajaran dalam jangka waktu tertentu. Kegiatan evaluasi di Prodi PAI dilaksanakan secara bervariasi. Hal ini bertujuan untuk mengetahui kemampuan dan keterampilan para mahasiswa. Dilihat dari bentuk macammacam penilaian yang dilakukan oleh dosen pengampu mata kuliah Al-Islam dan kemuhammadiyahan yang meliputi penilaian untuk mengukur kemampuan hard skill, dan soft skill. Penilaian hard skiil dilakukan dengan tes tulis, tes lisan, dan penugasan. Sedangkan penilaian soft skiil dilakukan dengan pengamatan terhadap kemampuan presentasi, kemampuan bertanya dan menjawab, kerjasama dalam kelompok, serta kedisiplinan untuk hadir dalam perkuliahan.

Sejalan dengan Ainiyah menuturkan evaluasi dari Keberhasilan pendidikan karakter melalui mata kuliah AIK ini tentunya tidak dapat dinilai dengan tes formatif atau sumatif yang dinyatakan dalam skor. Tetapi tolak ukur dari keberhasilan pendidikan karakter adalah terbentuknya peserta didik yang berkarakter; berakhlak, berbudaya, santun, religius, kreatif, inovatif yang teraplikasi dalam kehidupan disepanjang hayatnya. Oleh karena itu tentu tidak ada alat evaluasi yang tepat dan serta merta dapat menunjukkan keberhasilan pendidikan karakter.

Dalam pengembangan potensi mahasiswa selain akademik dikembangkan pula potensi mahasiswa dari aspek Nonakademik. Beberapa kegiatan keorganisasian yaitu Ikatan Mahasiswa Muhammadiyah dibentuk untuk menampung berbagai macam potensi mahasiswa. Berdasarkan data hasil wawancara bersama dosen pengampu mata kuliah AIK terdapat berbagai kegiatan yang dilakukan oleh mahasiswa terutama dalam segi keagamaan atau keislaman. Adapun dilihat dari aktivitas mahasiswa dari segi keagamaan. Hal ini menjadi nilai plus jika dibandingkan dengan perguruan tinggi lainnya, khususnya dalam bidang keagamaan/religius. Kadar religiusitas adalah tingkatan sejauh mana pengetahuan, keyakinan, pelaksanaan dan penghayatan seseorang terhadap agamanya. Pembagian aspek-aspek religiusitas meliputi lima dimensi, yaitu dimensi ideologis, dimensi ritual, dimensi pengalaman dan penghayatan beragama, dimensi pengetahuan, serta dimensi konsekuensi.

\section{KESIMPULAN}

Berdasarkan hasil dan pembahasan di atas, maka dapat ditarik kesimpulan adalah sebagai berikut:

1. pada matakuliah AIK1 penanaman pendidikan karakter diantaranya adalah Pertama, Menyampaikan pengetahuan tentang kesabaran dan kegigihan Rasulullah Saw. Kedua, Menanamkan keyakinan sikap optimis, dan Ketiga, Menanamkan pada mahasiswa untuk berfikir positif dalam keadaan dan kondisi apapun jangan mudah putus asa, sebagaimana perjuangan Nabi Muhammad Saw dan perjuangan KH. Ahmad Dahlan dalam mensyiarkan dakwah Islam pasti ada tantangan dan hambatannya. Sementara itu, pada mata kuliah AIK2, mahasiswa di arahkan untuk dapat merealisasikan pesan yang terkandung dalam Al-Qur'an surat AlMaun, diantaranya adalah Pertama, larangan menghardik anak yatim dan memberikan kepedulian kepada mereka yang yatim, Kedua, memberi makan dan berbagi kepada fakir miskin. Sehingga dengan pendidikan karakter tersebut mahasiswa benar-benar memahami pembelajaran Al-Islam dan Kemuhammadiyahan. Setelah proses 
pembelajaran AIK pada Prodi PAI di Universitas Muhammadiyah Tangerang berlangsung. Maka hal yang paling penting dari kegiatan belajar dan mengajar adalah mengevaluasi pembelajaran AIK.

2. Kegiatan evaluasi di Prodi PAI dilaksanakan secara bervariasi. Hal ini bertujuan untuk mengetahui kemampuan dan keterampilan para mahasiswa. Dilihat dari bentuk macam-macam penilaian yang dilakukan oleh dosen pengampu mata kuliah Al-Islam dan kemuhammadiyahan yang meliputi penilaian untuk mengukur kemampuan hard skill, dan soft skill. Penilaian hard skiil dilakukan dengan tes tulis, tes lisan, dan penugasan. Sedangkan penilaian soft skiil dilakukan dengan pengamatan terhadap kemampuan presentasi, kemampuan bertanya dan menjawab, kerjasama dalam kelompok, serta kedisiplinan untuk hadir dalam perkuliahan.

\section{DAFTAR PUSTAKA}

Ainiyah, Nur. 2013. "Pembentukan Karakter Melalui Pendidikan Agama Islam", Jurnal Al-Ulum: Vol.13 No.1 Juni.

Amelia. Kuncahyono. 2018. "Evaluasi Pembelajaran Berbasis Islam Kemuhammadiyahan Sebagai Internalisasi Penguatan Pendidikan Karakter Siswa Di SD Muhammadiyah Kota Malang", Jurnal Bidang Pendidikan Dasar: Vol.2 No.2 Juni.

Arifin, Syamsul. 2015. "Rekonstruksi AlIslam dan Kemuhammadiyahan (AIK) Perguruan Tinggi Muhammadiyah Sebagai Praksis Pendidikan Nilai”, Jurnal Edukasi Pendidikan Agama dan Keagamaan: Vol.13 No.2 Agustus.
Dirjen Pendidikan Tinggi Kemenristek Dikti. 2013. Kerangka Acuan Pendidikan Karakter.

Handayani, Puspita. "Pendidikan Karakter Matakuliah Al-Islam Dan Kemuhammadiyahan (Aik-1) Terhadap Perilaku Mahasiswa Fakultas Ekonomi Dan Bisnis Umsida", Prosiding Seminar Nasional Pendidikan : Tema "Desain Pembelajaran Di Era Asean Economic Community (Aec) Untuk Pendidikan Indonesia Berkemajuan" Fakultas Keguruan Dan Ilmu Pendidikan Universitas Muhammadiyah Sidoarjo.

Khilmiyah. Syamsudin. 2016. "Evaluasi Pembelajaran AIK Dengan Pendekatan Social Emosional Learning (Sel) Dalam Membentuk Karakter dan Akhlak Mulia Mahasiswa Universitas Muhammadiyah Yogyakarta", Laporan Hasil Penelitian Hibah Unggulan Program Studi.

Silvie. Kurnia. 2018. "Penanaman NilaiNilai Kemuhammadiyahan Sebagai Penguatan Pendidikan Karakter Sejak Dini Di Tk Aisyiyah Bustanul Athfal 24 Kayu Putih, Jakarta Timur", Prosiding Seminar Nasional Pendidikan Era Revolusi "Membangun Sinergitas dalam Penguatan Pendidikan Karakter pada Era IR 4.0” Universitas Muhammadiyah Jakarta, Indonesia, 24 Maret.

Subarkah, Milana Abdillah. 2019. "Nilainilai Pendidikan Karakter dalam Warung Dhuafa", Jurnal Rausyan Fikr: Vol. 15 No.2 September.

Thoha, Chabib, dkk. 1999. Metodologi Pengajaran Agama, Yogyakarta : Pustaka Pelajar.

Winarni, Sri. 2013. "Integrasi Pendidikan Karakter dalam Perkuliahan", Jurnal Pendidikan Karakter: Vol.3 No.1. 